\title{
Genotype and phenotype of oral Candida albicans from patients infected with the human immunodeficiency virus
}

\author{
Michael J. McCullough, ${ }^{1}$ Bruce C. Ross, ${ }^{2}$ Brian D. Dwyer ${ }^{2}$ \\ and Peter C. Reade ${ }^{1}$
}

Author for correspondence: Peter C. Reade. Tel: +61 33410255. Fax: +61 33410339.

1 School of Dental Science,
Faculty of Medicine,
Dentistry and Health
Sciences, University of
Melbourne, 711 Elizabeth
Street, Melbourne 3000,
Australia
2 Fairfield Hospital for
Infectious Diseases,
Yarrabend Road, Fairfield,
Melbourne 3078, Australia

\begin{abstract}
Candida albicans has been shown to vary in its phenotypic expression with the progression of human immunodeficiency virus (HIV) infection. Isolates of $C$. albicans were obtained from 45 patients with HIV infection during the progression of their disease and differentiated using two methods. The first utilized the morphological characteristics of colonies, and the second method utilized a small portion of $C$. albicans DNA as a probe on Southern-transferred, EcoRl-digested C. albicans genomic DNA. In $67 \%$ of the patients a single strain of $C$. albicans, as determined by the DNA analysis, was isolated from each individual. The phenotypic expression of the genetically identical strains varied considerably over the experimental period with one morphotype being predominant. These results showed that the genotype of $C$. albicans persisted in the majority of HIV-infected individuals, but that the phenotypical expression of this strain changed. A novel finding in this study was that 18 strains of C. albicans had DNA which did not hybridize to the probe used.
\end{abstract}

Keywords: Candida albicans, HIV infection, oral candidosis, genetic typing, phenotype

\section{INTRODUCTION}

The most common fungal disease seen in the oral cavity is candidosis and the Candida species most often involved is $C$. albicans, although $C$. glabrata and $C$. tropicalis are occasionally isolated (MacFarlane, 1990). Oral candidosis is a common feature of patients with human immunodeficiency virus (HIV) infection. In 17 studies the reported frequency of the occurrence of oral candidosis in HIVinfected patients ranged from $11 \%$ to $96 \%$, with the majority of reports quoting frequencies greater than $50 \%$ (Holmstrup \& Samaranayake, 1990). The frequency of isolation of Candida and clinical signs of oral candidosis have been shown to increase with advancing HIV infection (Torssander et al., 1987; Korting et al., 1988). Candidosis of the oesophagus is one of the opportunistic infections seen in acquired immunodeficiency syndrome (AIDS) and its presence with HIV infection is diagnostic of AIDS according to the Centers of Disease Control (Atlanta, USA) surveillance definition (Greenspan et al., 1990).

It has been postulated that differences in pathogenicity exist between strains of $C$. albicans and many methods have been developed to divide $C$. albicans into strains or subpopulations which reflect their pathogenic potential.
These strain-differentiating methods have also been used for epidemiological purposes (Merz, 1990). Several investigators have suggested that some strains of $C$. albicans have a greater propensity to cause systemic, nosocomial and superficial infections than do other strains (Korting et al., 1988; Brawner \& Cutler, 1989).

The majority of the strain-differentiating methods are based on the phenotypic characteristics of the organism. One such method is based on the nature and extent of marginal fringing of streak colonies (Phongpaitchit et al., 1987). When this method was used by Hunter et al. (1989) on isolates from fatal infections, $67 \%$ had a discontinuous fringe morphotype whereas this morphotype was seen in only $11 \%$ of strains isolated from other infections. These authors postulated that there may be an association between virulence and the morphotype of strains of $C$. albicans.

Serotyping of $C$. albicans divides the species into two groups, types A and B (Hasenclever \& Mitchell, 1961a). Early studies using an animal model (Hasenclever \& Mitchell, 1961b) did not show a correlation between serotype and virulence. More recent studies have shown that there is an increased frequency of 5-fluorocytosine resistance in serotype B (Auger et al., 1979; Brawner et al., 1992), and have demonstrated that there is an increased 
pathogenic potential that correlates serotype B and immune status.

Recent advances in molecular biology have allowed the use of restriction enzyme analysis of genomic DNA to classify C. albicans at a subspecies level useful for epidemiological purposes (Magee et al., 1987; Smith et al., 1989; Matthews \& Burnie, 1989; Monod et al., 1990). The use of a species-specific repeated gene segment as a DNA probe in restriction enzyme analysis has enabled more highly detailed epidemiological studies because of the large number of different types defined by this technique (Fox et al., 1989; Scherer \& Stevens, 1988).

The aim of the current investigation was to assess the morphotype, serotype and genotype of oral mucosal candidal organisms in a group of HIV-infected patients over time to ascertain if these parameters changed during the experimental period.

\section{METHODS}

Patients. Sixty patients of the Fairfield Hospital for Infectious Diseases were entered into this study between November 1989 and April 1992 after approval was given by the Ethics Committee of that Hospital. All were diagnosed as group IV HIV infection according to the classification of the Centers for Disease Control (CDC), Atlanta, USA. After receiving informed consent, a complete oral examination was undertaken and oral samples were collected by the imprint culture method of Arendorf \& Walker (1980) and the oral rinse technique outlined by Samaranayake et al. (1986) for laboratory analysis. The patients were reviewed during their normal medical appointments when further oral samples were taken. At each examination the most recent assay of the patients' CD4-positive T lymphocytes as a percentage of total lymphocytes (cells $\mu \mathrm{l}^{-\mathbf{1}}$ ) was recorded as an indication of immune status.

Table 1. System of coding of the morphological features

\begin{tabular}{|lll|}
\hline Feature & Code & \multicolumn{1}{c|}{ Description } \\
\hline Fringe & 0 & Absent \\
distribution & 1 & Discontinuous; $<20 \%$ of margin \\
& 2 & Discontinuous; 20-50\% of margin \\
& 3 & Discontinuous; $>50 \%$ of margin \\
& 5 & Continuous at the periphery or \\
& & strands conspicuously fan shaped \\
& 7 & Continuous; filamentous outgrowths \\
& & parallel \\
Fringe width & 0 & Absent \\
& 2 & $<2$ mm \\
& 3 & $2-5$ mm \\
& 5 & $>5$ mm \\
& 0 & Absent \\
Fringe texture & 1 & Very coarse \\
& 2 & Coarse \\
& 3 & Intermediate \\
& 4 & Fine \\
\hline
\end{tabular}

Identification of Candida species. Yeast colonies were speciated by three methods. Firstly, each isolate was assessed for the production of germ tubes after incubation in horse serum at $37{ }^{\circ} \mathrm{C}$ in a shaking water bath for $2 \mathrm{~h}$. Secondly, they were assessed for the production of chlamydospores when inoculated under a sterile cover slip in the dark for $72 \mathrm{~h}$ on cornmeal agar (Oxoid) containing Tween 80 (Sigma). Finally, each isolate was tested for carbon assimilation by the API 20C AUX identification system (bioMerieux). Samples were separated as either $C$. albicans or Candida species other than albicans. The $C$. albicans samples were serotyped into group A or B by a slide agglutination test using the Iatron factor 6 rabbit antiserum (IF6) (\#RM 302-4, Iatron Laboratories). All samples were inoculated into $2 \mathrm{ml}$ of storage medium consisting of $100 \mathrm{ml}$ Luria broth (10 g tryptone, $5 \mathrm{~g}$ yeast extract powder, $10 \mathrm{~g} \mathrm{NaCl}$ in $1 \mathrm{l}$ sterile deionized water) and $30.5 \mathrm{ml}$ glycerol (BDH Chemicals) and stored at $-20^{\circ} \mathrm{C}$ until further analysis was performed. Only those patients who had $C$. albicans isolated on more than one occasion were used in this study.

Colony morphology. For morphotyping, stored yeast cells were resuscitated from $-20^{\circ} \mathrm{C}$ by culturing on Sabouraud's agar (Oxoid) at $37^{\circ} \mathrm{C}$ for $48 \mathrm{~h}$. Single colonies from these cultures were then streaked onto $2 \%(\mathrm{w} / \mathrm{v})$ malt agar (Oxoid) and incubated at $30^{\circ} \mathrm{C}$. After $24 \mathrm{~h}$ the yeast cells were suspended in sterile deionized water to give a distinct turbidity corresponding to $10^{7}-10^{8}$ cells $\mathrm{ml}^{-1}$ as described by Phongpaitchit et al. (1987). Agar plates containing 6\% (w/v) malt extract and $2 \%(\mathrm{w} / \mathrm{v})$ Difco special agar (Oxoid) were then inoculated with a single diametric streak of the test suspension using a sterile cotton wool swab. Cultures were incubated in the dark for $10 \mathrm{~d}$ at $30^{\circ} \mathrm{C}$ after which the streak characteristics of each inoculum were determined. A modified three digit coding system of numbers was allocated to the features of the colony streaks as outlined by Hunter et al. (1989). The initial digit represents the distribution, the second the width and the third the texture of the fringe. The numbering system for the various attributes is outlined in Table 1.

Genetic typing. For genetic typing, stored yeast cells were initially cultured on Sabouraud's agar (Oxoid) at $37^{\circ} \mathrm{C}$ for $24 \mathrm{~h}$. A single yeast colony from these cultures was then inoculated into $10 \mathrm{ml}$ YPD broth (1 $\mathrm{g}$ yeast extract, $2 \mathrm{~g}$ bactero-peptone and $2 \mathrm{~g} \mathrm{D}$-glucose in $100 \mathrm{ml}$ sterile water) and incubated overnight in a shaking water bath at $37^{\circ} \mathrm{C}$. Candida DNA was prepared by the method of Scherer \& Stevens (1987) except that the DNA was extracted five times with phenol (ICN Biomedicals)/chloroform (Prosana Laboratories) (1:1, v/v) prior to precipitation in 2 vols ethanol (Rhone-Poulenc Laboratories). Approximately $3 \mu \mathrm{g}$ of DNA was digested with 5 units EcoRI (Boehringer Mannheim) overnight at $37^{\circ} \mathrm{C}$ to ensure complete digestion. The DNA fragments were separated through a $0.7 \%(\mathrm{w} / \mathrm{v})$ agarose gel in TBE buffer $(89 \mathrm{mM}$ Tris base, $89 \mathrm{mM}$ Boric acid, $0.2 \mathrm{mM}$ EDTA) for $18 \mathrm{~h}$ at $70 \mathrm{~V}$. The DNA was transferred under vacuum to a positively charged nylon membrane (Boehringer Mannheim) which was then hybridized overnight in $50 \%(\mathrm{v} / \mathrm{v})$ formamide, $0.9 \mathrm{M} \mathrm{NaCl}$, $50 \mathrm{mM}$ sodium phosphate ( $\mathrm{pH} 7 \cdot 4$ ), $5 \mathrm{mM}$ EDTA, $0 \cdot 3 \%$ SDS, and $100 \mu \mathrm{g}$ denatured salmon sperm DNA ml with a digoxigenin-labelled species-specific probe. The probe, $27 \mathrm{~A}$, is an EcoRI fragment of $C$. albicans cloned into the plasmid vector pUC18 and was kindly supplied by Dr S. Scherer, University of Minnesota, Minneapolis, USA. For labelling, the EcoRI fragment $27 \mathrm{~A}$ was subcloned into plasmid pT7T3 (Pharmacia) and a digoxigenin-labelled RNA probe was prepared from the HindIII-digested plasmid with T7 RNA polymerase using a labelling kit supplied by Boehringer Mannheim. After hybridization the probe was detected using an alkaline phosphatase- 


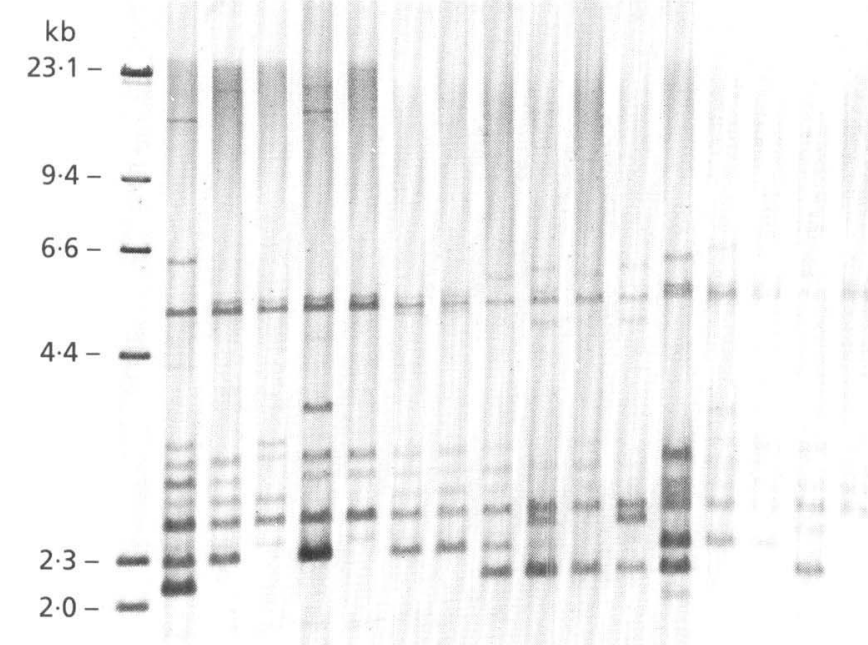

Fig. 1. Southern blot hybridization of EcoRIdigested Candida DNA from randomly selected oral isolates of 15 patients.

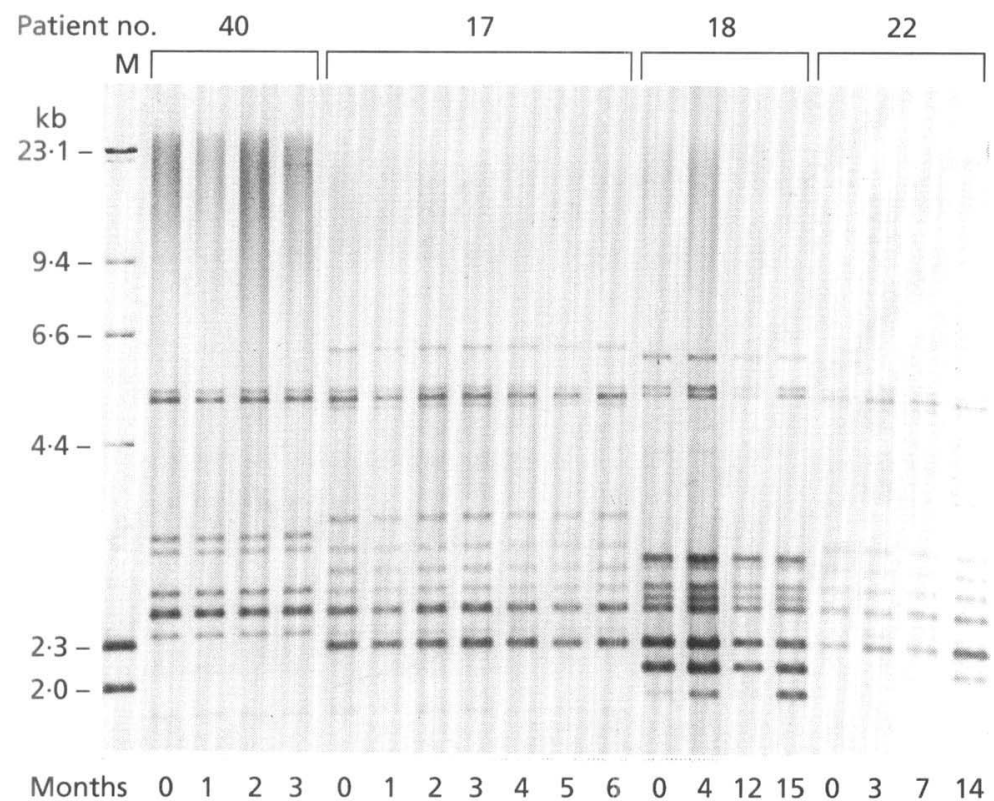

Fig. 2. Southern blot hybridization of EcoRIdigested Candida DNA from consecutive oral isolates. The lanes are grouped above for the same patient and the numbers below are the times in months at which the isolates were taken. The isolates taken at 0 and 12 months from patient 18 and the isolate taken at 14 months from patient 22 were genetically distinct from other isolates of those patients. These variations were reproducible when different colonies taken at the same time were processed.

conjugated antibody (Boehringer Mannheim) according to the manufacturer's instructions. This resulted in the ability to use a non-radioactive technique with markedly reduced background staining.

\section{RESULTS}

The 60 patients in this study have all died. The average survival time since diagnosis of AIDS (group IV HIV infection, CDC) (Greenspan et al., 1990) was 20.5 months with a range of 3-36 months.

Forty-five of the 60 patients were included for further analysis on the basis that $C$. albicans was isolated on more than one occasion during the experimental period. Of the remaining 15 patients, four had C. glabrata, two had $C$. krusei and two had $C$. tropicalis isolated, four had $C$. albicans isolated only once and three patients did not have any yeast isolated from their oral cavities during the experimental period. The 45 patients analysed had a total of 295 samples (mean $=6.5$ samples per patient) taken at various intervals ranging from 2 to 24 months (mean $=9 \cdot 3$ months). Of these 45 patients, $23(51 \%)$ had at some stage during the experimental period signs and symptoms of oral candidosis as diagnosed by the criteria of Greenspan et al. (1990). These patients were treated with either amphotericin, nystatin or fluconazole. Twenty of these 23 patients were in a concurrent fluconazole trial which consisted of $100 \mathrm{mg} \mathrm{d}^{-1}$ for 1 week and a maintenance dose of $50 \mathrm{mg}$ daily for approximately 2 months. Recurrence of oral candidosis occurred in $48 \%(11 / 23)$ of 


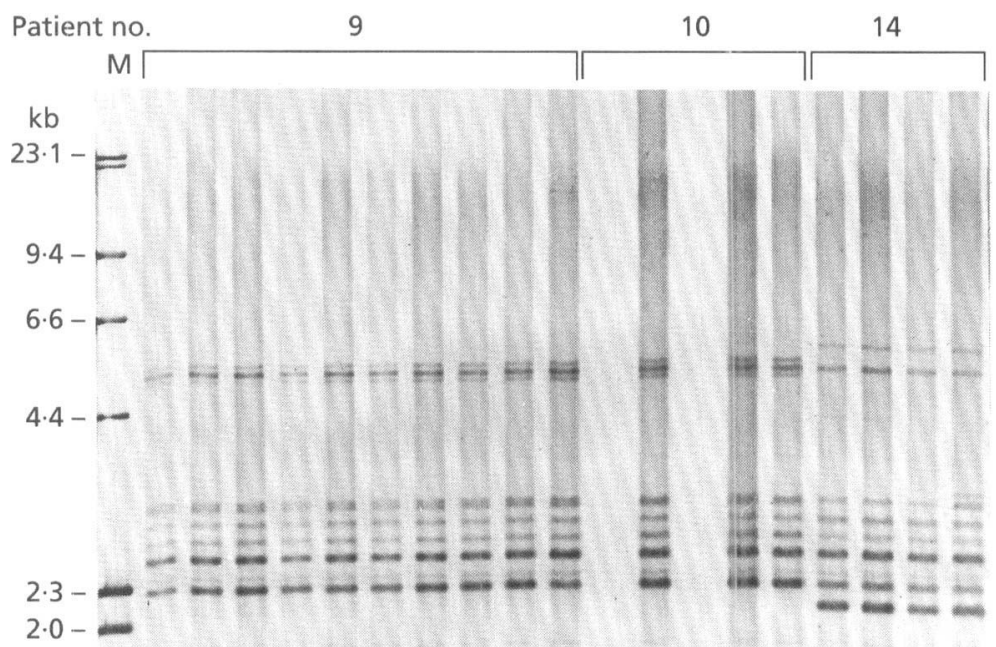

$\begin{array}{llllllllllllllllllll}\text { Months } & 0 & 1 & 2 & 9 & 10 & 11 & 12 & 17 & 18 & 19 & 0 & 2 & 7 & 9 & 10 & 0 & 1 & 2 & 3\end{array}$
Fig. 3. Southern blot hybridization of EcoRIdigested Candida DNA from consecutive oral isolates. The lanes are grouped above for the same patient and the numbers below are the times in months at which the isolates were taken. The isolates from patient 9 have two bands at $3 \mathrm{~kb}$ whilst those of patient 10 have one. Two of the isolates from patient 10,0 and 7 months, did not show any hybridization with the DNA probe used.
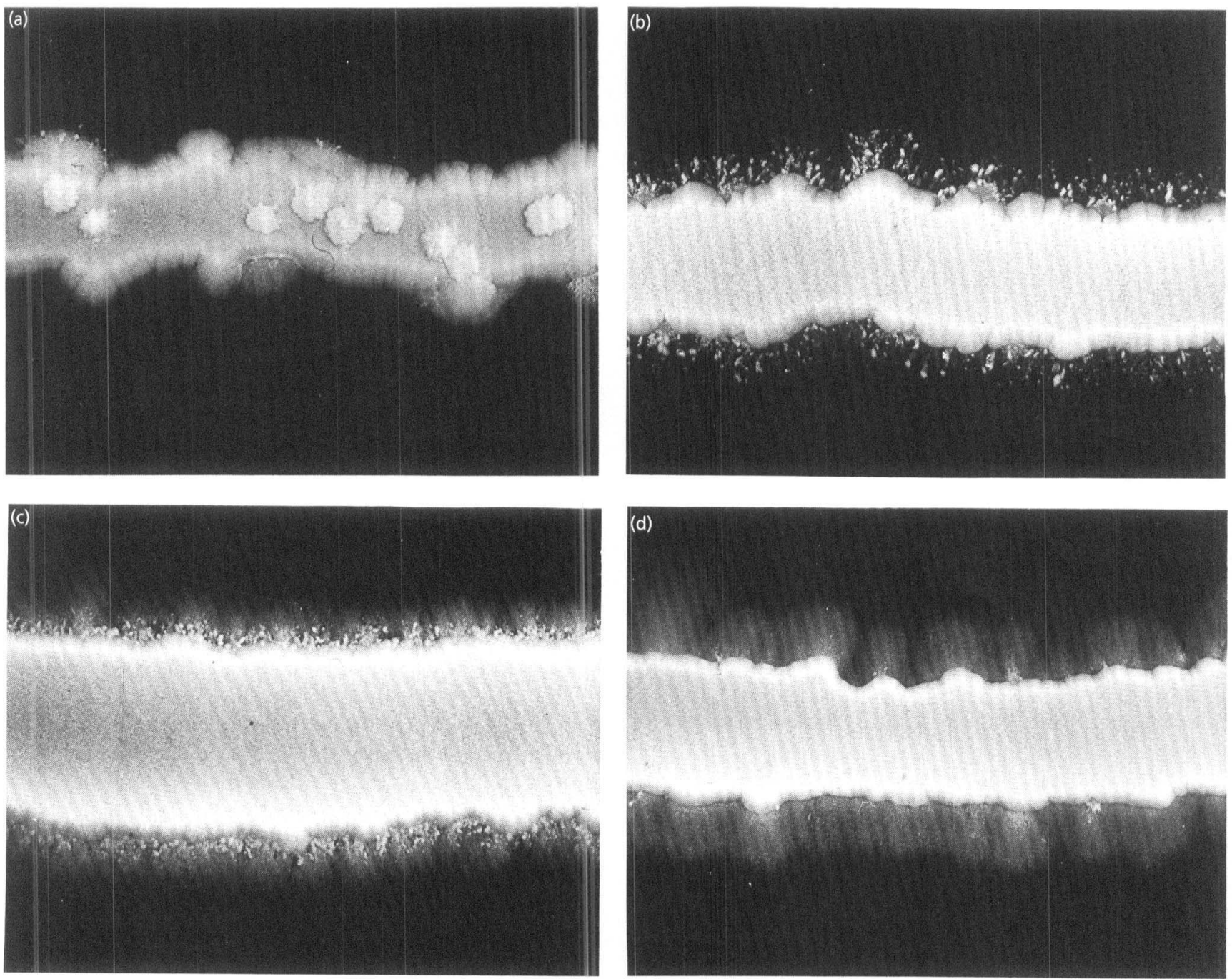

Fig. 4. Four morphotypes taken at different times from the same patient over a period of 9 months. The four morphotypes are (a) 123, (b) 731, (c) 522 and (d) 534. 
these patients after the medication was ceased. The average time for recurrence was 5.2 months (range $2-9 \cdot 5$ months).

\section{Genetic analysis}

Genetic typing of the $C$. albicans isolates by Southern blot hybridization showed significant variation in the banding patterns between isolates from different patients. This is illustrated in Fig. 1 where the DNA profiles of randomly selected $C$. albicans isolates from 15 patients are shown. This suggested the existence of a large number of different genetic types within the species which indicated this technique is useful for determining the identity of isolates. Analyses of all $C$. albicans isolates by genetic typing revealed that there were 60 genetically different strains isolated from the 45 patients. The majority (30/45) of the patients harboured one strain unique to that patient and this strain persisted over the experimental period (Fig. 2). Fifteen of the 45 patients $(33 \%)$ had two genetically different strains isolated during the experimental period. Of the 149 isolates from these 15 patients, $16 \%(25 / 149)$ were genetically different from the predominant strain. In each patient where another strain was isolated, the isolation was not consistently related to episodes of either clinical oral candidosis or antifungal therapy. No patient had more than two genetically different strains isolated during the experimental period. In $20 \%(9 / 45)$ of patients, 18 of their 74 isolates $(24 \%)$ had genomes which did not show any hybridization with the DNA probe used (Fig. 3). Each of these strains was regrown on three occasions and the species identification repeated and checked by an independent observer. On each of these three occasions the DNA was extracted before repeating genetic typing as outlined above. All of the 18 strains were shown to be $C$. albicans whose DNA did not hybridize to the probe $(27 \mathrm{~A})$ used in this study.

The slide agglutination test for serotyping $C$. albicans revealed that $88 \%(53 / 60)$ of the genetically different strains isolated were serotype A while the remaining $12 \%$ $(7 / 60)$ were serotype B.

\section{Morphological analysis}

Each patient examined had two or more $C$. albicans morphotypes isolated at different times during the study period. The average number of different morphotypes isolated from each patient was $4 \cdot 6$ with a range of between 2 and 11. As an example, the morphotypes shown in Fig. 4 were isolated from the same patient over a 9 month period. From the 45 patients, 37 different morphotypes were isolated. Thirty-seven of the 45 patients $(82 \%)$ had the morphotype 754 isolated at least once during the period of examination. This morphotype occurred in $27.5 \%$ of all isolates, whereas all other morphotypes occurred at a frequency less than $7 \%$.

The 295 isolates were divided into groups according to the percentage of CD4-positive $T$ lymphocytes against total lymphocytes (\% T4) at the time when each sample was taken. Eighty-three of the 295 isolates (28\%) were taken when the $\% \mathrm{~T} 4$ was less than $5 \%$, while $47 \%$ $(139 / 295)$ were taken when the $\%$ T4 was less than $10 \%$. $\chi^{2}$ analysis of the morphotypes of these groups $(\% \mathrm{~T} 4<5 \%$, v. $\% \mathrm{~T} 4>5 \% ;$ and $\% \mathrm{~T} 4<10 \%$, v. $\% \mathrm{~T} 4>10 \%)$ showed no significance $(P=0 \cdot 1$ and $P=0 \cdot 25$, respectively) in the occurrence of any one morphotype.

Similarly, when all the discontinuous fringe morphotypes were combined, and the distribution of this combination was compared according to the $\% \mathrm{~T} 4$ of each patient as grouped above, no significant relationship $(P=0.35$ and $P=0 \cdot 5$, respectively) between the discontinuous fringe morphotype and the declining immune status of the patients was found.

\section{DISCUSSION}

The rate of multiple isolation of $C$. albicans from the oral cavity of $\mathrm{HIV}$-infected patients in the present study was $67 \%$ which is similar to that of previous studies (Korting et al., 1988; Torssander et al., 1987). The finding in the present study that $51 \%(23 / 45)$ of patients developed clinical signs of oral candidosis also correlated well with the study of Korting et al. (1988) who found that $54 \cdot 2 \%$ $(13 / 24)$ of their patients with AIDS were observed to develop clinical oral candidosis. A higher prevalence of $70 \%(21 / 30)$ of oral candidosis was reported by Miyasaki et al. (1992) in their study of HIV seropositive subjects. Such discrepancy may be due to patient selection or degree of immunosuppression of the selected group. In the present study the patients were chosen randomly from individuals regularly attending an out-patient clinic for HIV infection and had been diagnosed as category IV HIV infection (CDC) at the outset of the investigation. In the study of Miyasaki et al. (1992), the study group was not separated into any HIV staging classification and thus the degree of immunosuppression of this group was difficult to assess.

Several studies have investigated the genetic relatedness of $C$. albicans isolates by the use of probes $27 \mathrm{~A}$ (Fox et al., 1989) and Ca3 (Soll et al., 1991; Miyasaki et al., 1992) which represent the same family of repeated sequences (Sadhu et al., 1991). The observation of the genetic relatedness of the $C$. albicans strains from HIV-infected patients reported here differs from those previous studies.

We found that two-thirds of the patients had only one patient-specific strain isolated throughout the course of this study and that one-third had two genetically different strains isolated. This contrasts with the findings of Miyasaki et al. (1992) who found that none of their 30 patients had more than one strain of $C$. albicans isolated over the experimental period. Powderly et al. (1992) also found that by using the same genetic test as described here, all 39 isolates from their HIV-infected patients were a unique genetic type. This research, however, did not assess the temporal presence of $C$. albicans strains in these patients. Furthermore, Fox et al. (1989) showed that the DNA profile pattern using the $27 \mathrm{~A}$ probe was identical in 
the C. albicans isolated serially (2-18 months) from eight hospitalized, immunocompromised patients. In contrast, in a recent study using multilocus enzyme electrophoresis patterns of $C$. albicans isolates from bone marrow transplant patients over a 13 month period, Caugant \& Sandven (1993) found that three of their seven patients were colonized by more than one strain. This finding is similar to the results of our study as the number of times a genetically different strain was isolated from the group of patients who harboured two strains in the present study was small $(16 \%)$. The difference between these results may reflect the number of colonies sampled at each time point and the number of oral samples taken from each patient. The second strain may only be present in small numbers in the oral cavity by comparison with the more predominant strain. Throughout this study only one randomly chosen colony was analysed at any one sampling.

The fact that the second, less predominant strain was not consistently isolated during clinical oral lesions, or during treatment with antifungal medication suggested that this strain is not more virulent or more drug resistant. Similar observations have been made in other studies (Miyasaki $e t$ al., 1992; Whelan et al., 1990). Recently, Gallagher et al. (1992) have shown that phenotypically switched variants of $C$. albicans can develop decreased azole susceptibility even though these strains remained genetically identical. These authors have shown, thereby, that it is not necessary to have alterations in the genetic type of strain for there to be changes in the drug susceptibility of the organism. Blumberg et al. (1992) provided clinical evidence to support this contention by showing that the same genetic strain of $C$. albicans was isolated from a patient with fungemia in whom fluconazole failed to eradicate the organism. There was a marked decrease in the in vitro susceptibility of these genetically identical strains throughout the course of this patient's infection.

The lack of hybridization of 18 strains of $C$. albicans with the species-specific $27 \mathrm{~A}$ probe has not previously been reported. All of these 18 strains were regrown, speciated independently by the use of the API 20C AUX identification system (bioMerieux). The DNA was exhaustively purified during the extraction procedure before Southern blot hybridization. In each case the strains were $C$. albicans and their DNA failed to hybridize with the $27 \mathrm{~A}$ probe. This procedure was repeated on three occasions when the original findings were confirmed. The most likely explanations are that the isolates may be another species of Candida which are phenotypically identical to C. albicans but genetically distinct, or that the probe target is not present in all strains of $C$. albicans.

The results of the serotyping of the $C$. albicans isolates presented here $(88 \%$ serotype $A$ and $12 \%$ serotype B) were similar to the occurrence of serotypes from early studies (Martin \& Lamb, 1982) but differed from recent studies of the prevalence of serotype $B$ in the immunocompromised host (Brawner et al., 1992; Brawner \& Cutler, 1989). In a study comparing different methods of serotyping C. albicans, Brawner (1991) found that the IF6 rabbit antiserum may slant results in favour of type A prevalence by as much as $24 \%$ due to autoagglutination of serotype B isolates. This may have increased the prevalence of serotype $A$ in the present study.

The wide variation in the morphotypes of each patient's genetically identical $C$. albicans isolates (mean $=4 \cdot 6$ per patient) presented here raises the question of the reproducibility of this technique. Hunter \& Fraser (1989) recently analysed the discrimination and reproducibility of four $C$. albicans typing methods including morphotyping. They found that the reproducibility of the colonial fringe characteristic in their in vitro study was $89 \%$. The results of our study suggest a much lower reproducibility which may reflect the phenomena of phenotypic switching (Anderson \& Soll, 1987; Slutsky et al., 1987) or subtle phenotypic changes in the organism as a result of local environmental pressure.

The high prevalence of the morphotype 754 in this study $(82 \%$ of patients and $27.5 \%$ of total isolates) does not have a ready explanation. A recent study of morphotypes of $C$. albicans from HIV-infected patients by Oliver \& Reade (1993) found the morphotype 724 to be isolated from $52 \%$ of ARC (AIDS-related complex) and AIDS patients, whilst this morphotype was not isolated from HIV asymptomatic patients. These two morphotypes (754 and 724) differ only in the width of the fringe which may reflect technical variations, but both had continuous fine fringes. Oliver \& Reade (1992) postulated that there may be an association between progressive immunosuppression from HIV posterity to AIDS and a lack of antibody response to this morphotype and that this change in phenotypic expression may have predictive significance for subsequent disease progression. The findings from the present study showed that morphotype 754 was common in category IV HIV-infected patients, but was not related to their degree of immunosuppression as expressed by the percentage CD4-positive T lymphocytes.

Hunter et al. (1989) suggested that there was an association between the discontinuous fringe morphotype and fatal deep infections. They made this association by combining the morphotypes with the initial digit 1,2, 3 and 5 . When the same combination of morphotypes was made in our study there was no significant relationship with declining immune status. This result supports the theory of Hunter et al. (1989) that the fringe characteristic is a reflection of anatomical source of the isolate rather than reflecting an association with host immune status. Whether these morphotypes are directly related to any increased virulence of the organism remains unclear and warrants further research. It may be that the changing morphotypes of genetically identical strains of $C$. albicans within individuals over time represents switched variants, and in the light of the research by Gallagher et al. (1992) and Blumberg et al. (1992) this may have a bearing on changes in the susceptibility of these strains to antifungal agents.

The results of the present study showed that the same genetic strain of oral C. albicans isolated persisted in the majority of category IV HIV-infected individuals, but 
that the phenotypical expression of this strain changed with time.

\section{ACKNOWLEDGEMENTS}

This work was supported by the Australian Commonwealth AIDS Research Grant Committee. The authors would like to thank the staff of the Pathology Department of Fairfield Hospital for Infectious Diseases for their assistance and Kate Fletcher for her help in preparing the manuscript.

\section{REFERENCES}

Anderson, J. M. \& Soll, D. R. (1987). Unique phenotype of opaque cells in the white-opaque transition of Candida albicans. J Bacteriol 169, 5579-5588.

Arendorf, T. M. \& Walker, D. M. (1980). The prevalence and intraoral distribution of Candida albicans in man. Arch Oral Biol 25, 1-10.

Auger, P., Dumas, C. \& Joly, J. (1979). A study of 666 strains of Candida albicans: correlation between serotype and susceptibility to 5-fluorocytosine. J Infect Dis 139, 590-594.

Blumberg, H. M., Hendershot, E. F. \& Lott, T. J. (1992). Persistence of the same Candida albicans strain despite fluconazole therapy. Diagn Microbiol Infect Dis 15, 545-547.

Brawner, D. L. (1991). Comparison between methods for serotyping of Candida albicans produces discrepancies in results. J Clin Microbiol 29, 1020-1025.

Brawner, D. L. \& Cutler, J. E. (1989). Oral Candida albicans isolates from non-hospitalized normal carriers, immunocompetent hospitalized patients, and immunocompromised patients with or without acquired immunodeficiency syndrome. $J$ Clin Microbiol 27, 1335-1341.

Brawner, D. L., Anderson, G. L. \& Yuen, K. Y. (1992). Serotype prevalence of Candida albicans from blood culture isolates. J Clin Microbiol 30, 149-153.

Caugant, D. A. \& Sandven, P. (1993). Epidemiological analysis of Candida albicans strains by multilocus enzyme electrophoresis. J Clin Microbiol 31, 215-220.

Fox, B. C., Mobley, H. L. T. \& Wade, J. C. (1989). The use of a DNA probe for epidemiological studies of candidiasis in immunocompromised hosts. J Infect Dis 159, 488-494.

Gallagher, P. J., Bennet, D. E., Henman, M. C., Russel, R. J., Flint, S. R., Shanley, D. B. \& Coleman, D. C. (1992). Reduced azole susceptibility of oral isolates of Candida albicans from HIV-positive patients and a derivative exhibiting colony morphology variation. J Gen Microbiol 138, 1901-1911.

Greenspan, D., Schiodt, M., Greenspan, J. S. \& Pindborg, J. J. (1990). AIDS and the Mouth. Copenhagen: Munksgaard.

Hasenclever, H. F. \& Mitchell, W. O. (1961a). Antigenic studies of Candida. I. Observation of two groups in Candida albicans. $J$ Bacteriol 82, 570-573.

Hasenclever, H. F. \& Mitchell, W. O. (1961b). Antigenic studies of Candida. III. Comparative pathogenicity of Candida albicans group A, Group B and Candida stellatoidea. J Bacteriol 82, 578-581.

Holmstrup, P. \& Samaranayake, L. P. (1990). Acute and AIDSrelated oral candidosis. In Oral Candidosis, pp. 133-155. Edited by L. P. Samaranayake \& T. W. MacFarlane. London: Wright.

Hunter, P. R. \& Fraser, C. A. M. (1989). Application of a numerical index of discriminatory power to a comparison of four physiochemical typing methods for Candida albicans. J Clin Microbiol 27, 2156-2160.

Hunter, P. R., Fraser, C. A. \& Mackenzie, D. W. (1989). Morpho- type markers of virulence in human candidal infections. $J$ Med Microbiol 28, 85-91.

Korting, H. C., Ollert, M., Georgii, A. \& Froschl, M. (1988). In vitro susceptibilities and biotypes of Candida albicans isolates from the oral cavities of patients infected with human immunodeficiency virus. J Clin Microbiol 26, 2626-2631.

MacFarlane, T. W. (1990). Ecology and epidemiology of Candida. In Oral Candidosis, pp. 21-46. Edited by L. P. Samaranayake \& T. W. MacFarlane. London: Wright.

Magee, B. B., D'Souza, T. M. \& Magee, P. T. (1987). Strain and species identification by restriction fragment length polymorphisms in the ribosomal DNA repeat of Candida species. J Bacteriol 169, 1639-1643.

Martin, M. V. \& Lamb, D. J. (1982). Frequency of Candida albicans serotypes in patients with denture-induced stomatitis and in normal denture wearers. J Clin Pathol 35, 888-891.

Matthews, R. \& Burnie, J. (1989). Assessment of DNA fingerprints for rapid identification of outbreaks of systemic candidiasis. $\mathrm{Br} \mathrm{Med}$ J 298, 354-357.

Merz, W. G. (1990). Candida albicans strain delineation. Clin Microbiol Rev 3, 321-334.

Miyasaki, S. H., Hicks, J. B., Greenspan, D., Polacheck, I., MacPhail, L. A., White, T. C., Agabian, N. \& Greenspan, J. S. (1992). The identification and tracking of Candida albicans isolates from oral lesions in HIV-seropositive individuals. I Acquired Immune Defic Syndr 5, 1039-1046.

Monod, M., Porchet, S., Baudraz-Rosselet, F. \& Frenk, E. (1990). The identification of pathogenic yeast strains by electrophoretic analysis of their chromosomes. J Med Microbiol 32, 123-129.

Oliver, A. J. \& Reade, P. C. (1993). Morphotypes of oral isolates of Candida albicans from patients infected with the human immunodeficiency virus. J Med Vet Mycol 31, 289-297.

Phongpaitchit, S., Mackenzie, D. W. R. \& Fraser, C. (1987). Strain differentiation of Candida albicans by morphotyping. Epidemiol Infect 99, 421-428.

Powderly, W. G., Robinson, K. \& Keath, E. (1992). Molecular typing of Candida albicans isolated from oral lesions of HIV-infected individuals. AIDS 6, 81-84.

Sadhu, C., McEachern, M. J., Rustchenko-Bulgac, E. P., Schmid, J., Soll, D. R. \& Hicks, J. B. (1991). Telomeric and dispersed repeat sequences in Candida yeasts and their use in strain identification. $J$ Bacteriol 173, 842-850.

Samaranayake, L. P., MacFarlane, T. W., Lamey, P. \& Ferguson, M. M. (1986). A comparison of oral rinse and imprint sampling techniques for the detection of yeast, coliform and Staphylococcus aureus carriage in the oral carriage. J Oral Pathol 15, 386-388.

Scherer, S. \& Stevens, D. A. (1987). Application of DNA typing methods to epidemiology and taxonomy of Candida species. J Clin Microbiol 25, 675-679.

Scherer, S. \& Stevens, D. A. (1988). A Candida albicans dispersed, repeated gene family and its epidemiologic applications. Proc Natl Acad Sci US A 85, 1452-1456.

Slutsky, B., Staebell, M., Anderson, J., Risen, L., Pfaller, M. \& Soll, D. R. (1987). 'White-opaque transition': a second high-frequency switching system in Candida albicans. J Bacteriol 169, 189-197.

Smith, R. A., Hitchcock, C. A., Evans, E. G., Lacey, C. J. \& Adams, D. J. (1989). The identification of Candida albicans strains by restriction fragment length polymorphism analysis of DNA. J Med Vet Mycol 27, 431-434.

Soll, D. R., Galask, R., Schmid, J., Hanna, C., Mac, K. \& Morrow, B. (1991). Genetic dissimilarity of commensal strains of Candida spp. 
carried in different anatomical locations of the same healthy women. J Clin Microbiol 29, 1702-1710.

Torssander, J., Morfeldt-Manson, L., Biberfeld, G., Karlsson, A., Putkonen, P. \& Wasserman, J. (1987). Oral Candida albicans in HIV infection. Scand J Infect Dis 19, 291-295.

Whelan, W. L., Kirsch, D. R., Kwon-Chung, K. J., Wahl, S. M. \&
Smith, P. D. (1990). Candida albicans in patients with the acquired immunodeficiency syndrome: absence of a novel of hypervirulent strain. J Infect Dis 162, 513-518.

Received 10 August 1993; accepted 29 October 1993. 